\section{Commentary: Our patients deserve our patience}

\author{
William C. Frankel, MD, \\ Michael Z. Tong, MD, MBA, and Aaron J. Weiss, MD
}

In this single-center retrospective study from the Netherlands, Çelik and colleagues ${ }^{1}$ report the outcomes over 3 decades of 4404 patients who underwent surgical aortic valve replacement (SAVR). The mean survival for the overall cohort was 13.8 years, and survival relative to an age-, sex-, and yearmatched population was $85.8 \%$ and $60.4 \%$ for the overall cohort and $92.4 \%$ and $73.8 \%$ for the isolated SAVR cohort at 10 and 20 years, respectively. The authors argue that the latter 2 rates in particular should serve as benchmarks for future long-term transcatheter aortic valve replacement (TAVR) studies. Furthermore, despite increasing rates of comorbidities and concomitant procedures, operative mortality decreased from $2.7 \%$ (first decade) to $1.8 \%$ (final decade), and long-term survival remained stable. The authors should be commended for their results and requisite commitment to continuous improvement across all phases of cardiovascular care in the face of increasing patient and case complexity.

Although these results may not dramatically affect the current paradigm for aortic valve replacement, they are a welcome addition to the existing literature further demonstrating the excellent durability and long-term survival of contemporary SAVR. ${ }^{2-6}$ This is in stark contrast to a paucity of rigorous data regarding intermediate- and long-term outcomes for TAVR. Nevertheless, over the last decade, TAVR has incrementally secured approval from the Food and Drug Administration for patients with severe aortic stenosis from extreme to low surgical risk. Moreover, the most recent American College of Cardiology/American Heart Association guidelines endorse both TAVR and SAVR as reasonable options for low- and intermediate-risk patients between 65 and 80 years old. ${ }^{7}$

From the Department of Thoracic and Cardiovascular Surgery, Heart, Vascular and Thoracic Institute, Cleveland Clinic, Cleveland, Ohio.

Disclosures: Dr Tong has received speaking honorarium and consulting fees from $\mathrm{Ab}$ bott (Chicago, Ill), and Abiomed (Danvers, Mass). All other authors reported no conflicts of interest.

The Journal policy requires editors and reviewers to disclose conflicts of interest and to decline handling or reviewing manuscripts for which they may have a conflict of interest. The editors and reviewers of this article have no conflicts of interest.

Received for publication April 30, 2021; revisions received April 30, 2021; accepted for publication May 3, 2021; available ahead of print May 7, 2021.

Address for reprints: Aaron J. Weiss, MD, Department of Thoracic and Cardiovascular Surgery, Heart, Vascular, and Thoracic Institute, Cleveland Clinic, 9500 Euclid Ave, Desk J4-1, Cleveland, OH 44915 (E-mail: weissa2@ ccf.org).

J Thorac Cardiovasc Surg 2022;164:1752-3

$0022-5223 / \$ 36.00$

Copyright (c) 2021 by The American Association for Thoracic Surgery

https://doi.org/10.1016/j.jtcvs.2021.05.004

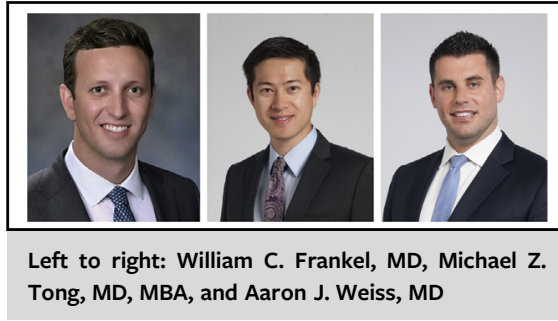

CENTRAL MESSAGE

In this single-center retrospective study, long-term outcomes after surgical aortic valve replacement were excellent and remained stable over time in the face of increasing case complexity.

There are several important limitations to the American College of Cardiology/American Heart Association guidelines and implied equipoise between TAVR and SAVR. First, the age range included in this recommendation is not supported by any evidence and extends almost 10 years below the mean patient age in the landmark low-risk TAVR trials. The aforementioned trials were also constructed based on surgical risk rather than age or life expectancy, rendering further expansion of TAVR to younger patients based on a false equivalency. Second, no randomized clinical trial to date has reported the outcomes of low- or intermediate-risk patients after TAVR beyond 5 years, and it remains unclear the extent to which complications such as a permanent pacemaker or paravalvular leak may adversely impact long-term outcomes. In fact, initial studies comparing outcomes in TAVR versus SAVR for low-risk patients-including a patient-level meta-analysis from the same author-have even signaled an increased risk of mortality associated with TAVR beyond 2 years. ${ }^{8}$ In addition, younger patients with a reasonable life expectancy may require subsequent aortic valve interventions during their lifetime. An initial strategy of TAVR may increase the likelihood of future SAVR, particularly in patients with small annular diameters. Albeit in a greater-risk population, initial studies have reported an early mortality of $\sim 20 \%$ following TAVR explantation, ${ }^{9}$ far exceeding the risk of reoperative SAVR. ${ }^{10}$

In summary, this manuscript is an important reminder to continue to be patient and measured while awaiting more rigorous long-term comparative data before further expansion of TAVR, especially to low-risk patients with a greater projected life expectancy. 


\section{References}

1. Çelik M, Durko AP, Bekkers JA, Oei FBS, Mahtab EAF, Bogers AJJC. Outcomes of surgical aortic valve replacement over three decades. J Thorac Cardiovasc Surg. 2022;164:1742-51.e8.

2. Jamieson WRE, Burr LH, Miyagishima RT, Germann E, Macnab JS, Stanford E, et al. Carpentier-Edwards supra-annular aortic porcine bioprosthesis: clinical performance over 20 years. J Thorac Cardiovasc Surg. 2005;130:994-1000.

3. David TE, Armstrong S, Maganti M. Hancock II bioprosthesis for aortic valve replacement: the gold standard of bioprosthetic valves durability? Ann Thorac Surg. 2010;90:775-81.

4. Forcillo J, Pellerin M, Perrault LP, Cartier R, Bouchard D, Demers P, et al. Carpentier-Edwards pericardial valve in the aortic position: 25-years experience. Ann Thorac Surg. 2013;96:486-93.

5. Johnston DR, Soltesz EG, Vakil N, Rajeswaran J, Roselli EE, Sabik JF III, et al. Long-term durability of bioprosthetic aortic valves: implications from 12,569 implants. Ann Thorac Surg. 2015;99:1239-47.
6. Holmgren A, Enger TB, Näslund U, Videm V, Valle S, Evjemo KJD, et al. Longterm results after aortic valve replacement for bicuspid or tricuspid valve morphology in a Swedish population. Eur J Cardiothorac Surg. 2021;59:570-6.

7. Otto CM, Nishimura RA, Bonow RO, Carabello BA, Erwin JP III, Gentile F, et al 2020 ACC/AHA guideline for the management of patients with valvular heart disease: a report of the American College of Cardiology/American Heart Association Joint Committee on clinical practice guidelines. J Am Coll Cardiol. 2021;77:e25-197.

8. Celik M, Milojevic MM, Durko AP, Oei FBS, Bogers AJJC, Mahtab EAF. Mortality in low-risk patients with aortic stenosis undergoing transcatheter or surgical aortic valve replacement: a reconstructed individual patient data meta-analysis. Interact Cardiovasc Thorac Surg. 2020;31:587-94.

9. Fukuhara S, Brescia AA, Deeb GM. Surgical explantation of transcatheter aortic bioprostheses: an analysis from the Society of Thoracic Surgeons Database. Circulation. 2020;142:2285-7.

10. Naji P, Griffin BP, Sabik JF, Kusunose K, Asfahan F, Popovic ZB, et al. Characteristics and outcomes of patients with severe bioprosthetic aortic valve stenosis undergoing redo surgical aortic valve replacement. Circulation. 2015;132:1953-60.

\section{Commentary: Long-term outcomes of surgical aortic valve replacement: Difficult to match!}

\author{
Manuel J. Antunes, MD, PhD, DSc
}

Aortic valve replacement (AVR) has been performed routinely since the appearance of the valve prostheses in the late 1960s and early 1970s. ${ }^{1}$ The procedure is now one of the most frequent, in some centers the most frequent, cardiac surgery performed, essentially due to the "epidemic" of aortic stenosis in elderly patients. More than 2 million patients may have had the procedure in the last half century. Despite the many types of prostheses created, some never used, the surgical procedure has remained essentially the same, but improvement in the management of cardiopulmonary bypass and of myocardial protection has made AVR very secure, with some groups claiming close-to-zero mortality rates. It is so safe that it is usually one of the first procedures given to trainees.

\footnotetext{
From the Clinic of Cardiothoracic Surgery, Faculty of Medicine, University of Coimbra, Coimbra, Portugal.

Disclosures: The author reported no conflicts of interest.

The Journal policy requires editors and reviewers to disclose conflicts of interest and to decline handling or reviewing manuscripts for which they may have a conflict of interest. The editors and reviewers of this article have no conflicts of interest.

Received for publication May 6, 2021; revisions received May 6, 2021; accepted for publication May 7, 2021; available ahead of print May 14, 2021.

Address for reprints: Manuel J. Antunes, MD, PhD, DSc, Clinic of Cardiothoracic Surgery, Faculty of Medicine, University of Coimbra, 3000-548 Coimbra, Portugal (E-mail: mjantunes@fmed.uc.pt).

J Thorac Cardiovasc Surg 2022;164:1753-4

$0022-5223 / \$ 36.00$

Copyright (c) 2021 by The American Association for Thoracic Surgery

https://doi.org/10.1016/j.jtcvs.2021.05.018
}

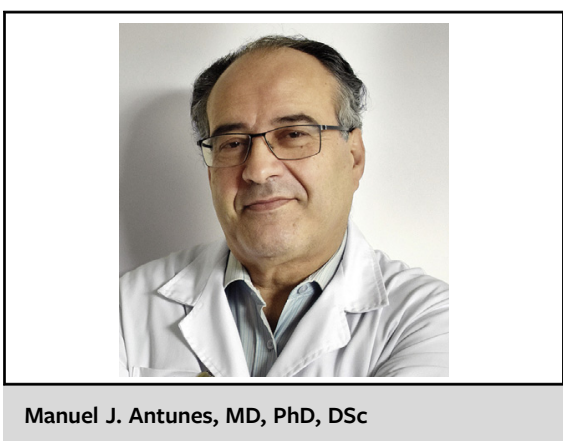

CENTRAL MESSAGE

AVR remains the gold standard for aortic valve treatment. Further reliable and unbiased comparative studies between TAVI and AVR are required to define the role of TAVI as a long-term alternative.

Hence, the results of AVR and the durability of current prostheses are now well established.

Nonetheless, there remains a significant number of patients who are either inoperable or very-high-risk for operation, especially in the elderly population. It was for these patients that transcatheter aortic valve implantation (TAVI) was introduced a decade ago (it received Food and Drug Administration approval in November 2011 for use in inoperable patients only). ${ }^{2}$ Since then, the use of TAVI has been expanded to less risky and younger patients, based on the favorable early results obtained in many randomized studies, usually designed to prove noninferiority 